DOI: 10.18554/cimeac.v11i3.5980

\title{
TOMADAS DE POSIÇÃO EM TEXTOS DE GRADUANDOS DA UFRN
}

\author{
TAKING POSITION IN TEXTS OF \\ UNDERGRADUATES OF UFRN
}

\author{
Rebecca Cruz Pinheiro* \\ Sulemi Fabiano-Campos*
}

\begin{abstract}
RESUMO: Nossa pesquisa surgiu do questionamento: "de que forma os alunos demonstram tomadas de posição em seus textos ao serem confrontados com artigos de opinião e os discursos que os perpassam?". A partir dessa pergunta, elaboramos como objetivo geral analisar como graduandos da Universidade Federal do Rio Grande do Norte (UFRN) de cursos das áreas de exatas, saúde e humanas tomam posição frente ao texto trabalhado em sala, isto é, como eles realizam processos de identificação ou contra-identificação. A pesquisa filia-se à Análise do Discurso de linha francesa, conforme postulada por Pêcheux (2014), e parte de uma abordagem qualitativa, seguindo o paradigma indiciário de Ginzburg (1989). Analisamos as respostas às questões e a produção das resenhas críticas propostas por nós a partir do texto "Poder e ética na pesquisa social" (DEBERT, 2003) por meio de disciplinas ofertadas pelo Departamento de Letras da UFRN. Como recorte metodológico para este trabalho, selecionamos o percurso de um aluno das coletas, isto é, analisamos suas respostas às questões e sua construção da resenha crítica a fim de compreendermos o caminho percorrido pelo aluno e como as tomadas de posição foram desenvolvidas. Em nossas análises, percebemos que há uma tendência de reproduzir o texto-fonte, marcada por paráfrases de sinonímia e até cópias do texto-fonte. Em relação às tomadas de posição frente aos discursos do texto-fonte, os alunos demonstraram se identificar com discursos que priorizam os direitos e interesses dos sujeitos de pesquisa, mas essa identificação não é plena.
\end{abstract}

Palavras-chave: Resenha crítica; Análise do Discurso; Tomadas de posição.

ABSTRACT: Our research arose from the question: "how do students demonstrate their position in their texts when confronted with articles and the discourses that persuade them?". From this questioning, we developed the general objective to analyze how students from the Federal University of Rio Grande do Norte (UFRN) of courses in the areas of exact, health and human position themselves in relation to the text worked on in class, that is, how it performs identification or counter-identification or processes. The research is affiliated to the French Discourse Analysis, as postulated by Pêcheux (2014)

\footnotetext{
* Secretaria de Estado da Educação, da Cultura, do Esporte e do Lazer do Rio Grande do Norte e pesquisadora da Universidade Federal do Rio Grande do Norte (UFRN). Contato: rebeccacruzpinheiro@gmail.com

**Universidade Federal do Rio Grande do Norte (UFRN). Contato: sulemifabiano@yahoo.com.br
} 
and uses a qualitative approach, following the indicative paradigm of Ginzburg (1989). We analyzed the answers to the questions and the production of the critical reviews proposed by us from the text "Poder e ética na pesquisa social" (DEBERT, 2003) through disciplines offered by the Department of Letters of UFRN. As a methodological approach, we select a student's trajectory from the collections, that is, we analyze their responses to questions and their construction of critical review, in order to understand the trajectory followed by the student and how the positions were developed. In our analysis, we noticed that there is a tendency to reproduce the source text, marked by synonymous' paraphrases and even plagiarism. Regarding the positions taken in relation to the discourses of the source text, the students demonstrated to identify with discourses that prioritize the rights and interests of the research subjects, but this identification is not complete.

Keywords: Critical review; Discourse analysis; Taking position.

\section{INTRODUÇÃO}

Por meio dos estudos desenvolvidos no Grupo de Estudos do Texto e do Discurso na Universidade Federal do Rio Grande do Norte (GETED - UFRN), juntamente com nossas experiências nos papéis de alunas e de professoras, surgiu o interesse de estudar a escrita de graduandos da UFRN em cursos de áreas distintas para que pudéssemos analisar como alunos de outros cursos tomam posição e dialogam com textos fornecidos em sala e como isso emerge na escrita de seus textos. Essas discussões, parcialmente apresentadas aqui, fazem parte da nossa pesquisa de mestrado, finalizada no ano de 2021 (PINHEIRO, 2021).

Assim, decidimos partir da teoria de Pêcheux (2014) acerca das tomadas de posição e utilizá-la como categoria para analisar textos de alunos de graduação de cursos de grandes áreas da UFRN (exatas, saúde e humanas, representadas pelos cursos de Matemática, Enfermagem e Jornalismo), por meio de disciplinas voltadas para leitura e produção de textos direcionada a esses cursos no semestre de 2019.2 e oferecidas pelo Departamento de Letras. Nosso objetivo é analisar, por meio de indícios linguísticos na produção de resenhas críticas e respostas às questões propostas, como graduandos da UFRN de cursos das áreas de exatas, saúde e humanas tomam posição frente aos discursos do texto trabalhado em sala. 
Para dar conta desse objetivo, além do embasamento em Pêcheux (2014), nossa pesquisa foi de natureza qualitativa-interpretativista, conforme definem Silva e Araújo (2017), por ter como foco a análise em profundidade dos sentidos construídos nos dados selecionados por meio da descriçãointerpretação. Dentro dessa perspectiva, seguimos o paradigma indiciário de Ginzburg (1989), em que o foco da investigação está nos indícios, pois se caracteriza como "um método interpretativo centrado nos resíduos, sobre os dados marginais, considerados reveladores" (GINZBURG, 1989, p. 149). Dessa forma, nossas pistas para a reconstrução dos efeitos de sentido são as expressões empregadas pelos alunos em seus textos.

Como dito anteriormente, o GETED realiza pesquisas sobre a escrita acadêmica e tem como pesquisas com textos de graduandos, por exemplo, a tese de Fabiano-Campos (2007), coordenadora do GETED, que analisou como se dá a incorporação de outros discursos em textos de alunos do curso de Letras e verificou que há uma tendência "consumista" do conhecimento, em que os discursos são mobilizados apenas para sustentar uma ideia, com textos parafrásticos, sem indícios de uma leitura mais aprofundada. Essas ideias são recuperadas por Barbosa e Fabiano-Campos (2014), em que, a partir da produção de alunos de licenciaturas, perceberam uma escrita permeada pelo acúmulo de informações, mas sem diálogo com a palavra do outro. Em ambos os trabalhos, percebe-se a pesquisa como meio de despertar no aluno uma atitude questionadora e de diálogo com saberes já estabelecidos, que levem o aluno à produção da palavra própria.

Também destacamos a dissertação de Vieira (2013), que estudou monografias de alunos de Letras a fim de analisar como esses pesquisadores iniciantes se utilizam e marcam a voz do outro e que efeitos de sentido esses usos suscitam na escrita das monografias. A partir de sua pesquisa, Vieira (2013) percebeu uma tendência dos alunos de reproduzirem discursos de autores, sem articular realmente a teoria ao seu próprio dizer, suas análises e/ou sua metodologia, de modo que o efeito gerado é o de promoção de um autor, conceito ou de uma teoria específica. 
Nossa pesquisa se une a essas na perspectiva de estudar textos de graduandos, mas apresenta novidade ao trabalhar com cursos de áreas distintas e com foco na tomada de posição dos alunos em suas produções em relação ao texto-fonte selecionado para coleta, de modo que podemos perceber de forma mais direta a influência dos discursos do texto-fonte que emergem nos textos dos alunos. Como detalhamos nas análises, desenvolvemos 4 questões relativas ao texto "Poder e ética na pesquisa social" (DEBERT, 2003), na qual a quarta questão diz respeito à produção de uma resenha crítica sobre o texto-fonte. Essas perguntas nos possibilitaram perceber um percurso de leitura do aluno por meio de suas respostas a questões de naturezas distintas e pela produção de sua resenha, como vemos nas análises.

\section{TOMADAS DE POSIÇÃO E CONCEITOS RELACIONADOS}

Tendo em vista nosso enfoque nas tomadas de posição elencadas por Pêcheux, explicitamos esse conceito e outros que o sustentam nesta seção.

Em sua obra "Semântica e discurso: uma crítica à afirmação do óbvio", Pêcheux (2014) indica a intenção de formular uma teoria (não subjetivista) da subjetividade, em que o sujeito não escapa ao assujeitamento a uma formação discursiva. No entanto, o próprio autor traz a possibilidade de esse sujeito se deslocar do que está posto como já-dito de uma formação discursiva porque há a abertura para tomadas de posição.

A partir do que é explanado por Pêcheux (2014) sobre a interpelação do indivíduo em sujeito do discurso por uma formação discursiva, podemos perceber que o sujeito não é totalmente assujeitado, mas inclinado para uma formação e até escolhe se assujeitar, já que conforme trata Althusser, base para Pêcheux, "[...] o indivíduo é interpelado como sujeito [livre] para livremente submeter-se às ordens do Sujeito, para aceitar, portanto [livremente] sua submissão [...]" (ALTHUSSER, 1985, p. 104 apud PÊCHEUX, 2014, p.124), ou seja, há uma submissão, mas ela se dá por meio de uma condução do sujeito e não por meio da força, fato que abre para um posicionamento. Assim, o sujeito é capaz de assumir uma posição, mesmo que afetado pela formação discursiva 
em que se insere, e são essas tomadas de posição que nos interessam neste trabalho.

Na concepção pecheutiana, a formação discursiva "é aquilo que, numa formação ideológica dada [...] determina o que pode e deve ser dito" (PÊCHEUX, 2014, p.160), ou seja, é essa formação discursiva, constituída a partir de formações ideológicas - e estas, compostas por um complexo conjunto de atitudes e representações, a partir da Ideologia - que representa o lugar da constituição do sentido, simulado como transparente para o sujeito pela formação discursiva, como desvinculado do "todo complexo com dominante" o interdiscurso -, de modo que os sentidos veiculados pela formação discursiva que dominam o sujeito parecem os únicos possíveis. Para Pêcheux (2014), é por meio de uma formação discursiva que o sujeito do discurso realiza tomadas de posição de identificação, contra-identificação e desidentificação.

A primeira modalidade de tomada de posição representa a identificação do sujeito do discurso com a formação discursiva que o domina, em que o sujeito, ao se identificar com os saberes da formação que o domina, os reproduz em seu discurso, sob um "trabalho de recobrimento-reprodução-reinscrição" (PÊCHEUX, 2014), muitas vezes sem perceber que utiliza esses sentidos construídos. Pêcheux (2014) trata essa modalidade como o comportamento do "bom sujeito", que aceita se submeter à formação discursiva, de modo que há uma "[...] superposição (um recobrimento) entre o sujeito da enunciação e o sujeito universal [...]" (PÊCHEUX, 2014, p.199), isto é, o sujeito reflete o que diz o sujeito universal da ideologia.

Conforme Pêcheux (2014) discorre, o sujeito é interpelado a se constituir como sujeito do discurso pela Ideologia, e seu assujeitamento a ela é justamente o funcionamento da forma-sujeito, esse sujeito histórico, afetado pela Ideologia, que encobre a realidade e faz parecer que as fronteiras entre as formações discursivas, o interdiscurso, está no próprio fio do discurso, o intradiscurso, como algo "já-dito".

A segunda modalidade de tomada de posição aponta para uma identificação com restrições, discordâncias e afastamentos, isto é, uma contraidentificação em relação à formação discursiva e à forma-sujeito que a organiza 
- que pode contribuir para heterogeneidade da formação discursiva. Conforme Pêcheux (2014, p. 199):

A segunda modalidade caracteriza o discurso do 'mau sujeito', discurso no qual o sujeito da enunciação 'se volta' contra o sujeito universal por meio de uma 'tomada de posição que consiste, desta vez em uma separação (distanciamento, dúvida, questionamento, contestação, revolta...) com respeito ao que o 'sujeito universal' Ihe 'dá a pensar': luta contra a evidência ideológica, sobre o terreno dessa evidência, evidência afetada pela negação, revertida a seu próprio terreno.

O autor ainda traz a interferência da forma-sujeito na aceitação ou rejeição de uma formação discursiva, como se houvesse uma pré-determinação de como o sujeito irá se posicionar de acordo com a interpretação que lhe é oferecida, mas percebemos que, embora haja uma influência da formação discursiva que domina (e sempre haverá), temos a possibilidade de um sujeito que é considerado "mau" porque toma uma posição de identificação parcial com a formação discursiva. Como não há afastamento total, a posição tomada pelo sujeito gera a incorporação de outras informações dentro da mesma formação, produzindo heterogeneidade dentro da formação discursiva.

Indursky, em seu estudo sobre as formações discursivas, interpretação e falha no ritual, afirma que "[...] esta segunda modalidade traz para o interior da formação discursiva o discurso-outro, a alteridade, e isto resulta em uma formação discursiva heterogênea" (INDURSKY, 2007, p. 81). Dessa forma, percebemos que a tomada de posição de contra-identificação produz mudanças dentro da própria formação discursiva, já que o sujeito não se afasta da formação em que se insere, mas traz considerações, reivindicações sobre os discursos que a compõem, modificando-a.

A terceira modalidade de tomada de posição, desidentificação, trata de um funcionamento da interpelação às avessas, de um "trabalho (transformaçãodeslocamento) da forma-sujeito [...] esse efeito de desidentificação se realiza paradoxalmente por um processo subjetivo e apropriação dos conceitos científicos e de identificação com as organizações políticas 'de tipo novo'[...]'” (PÊCHEUX, 2014, p. 201-202). A desidentificação, para o autor, seria o 
funcionamento do sujeito da ciência, um deslocamento da forma-sujeito, como indica a citação, como uma interpelação ao contrário, que possibilitaria a criação de formações discursivas do proletariado. Por ser uma espécie de tomada de posição utópica, inicialmente ela não nos interessa para este trabalho, que tem como foco a produção de graduandos e não uma escrita de construção de conhecimentos, que se aliaria à concepção de um sujeito da ciência.

O conceito de formação discursiva nos parece abstrato para que haja identificação ou contra-identificação em relação a ela, de modo que consideramos não ser adequado utilizar as tomadas de posição como relativas às formações, mas relativas aos discursos que são parte dessas formações, de modo que o conceito de formação discursiva aparece aqui não com uma visão homogeneizante, de definição absoluta do que pode e deve ser dito, mas como espaço em que se agrupam discursos similares em suas funções e temáticas. Nosso trabalho visa ao início do deslocamento do foco nas formações discursivas para o discurso, como percebemos ser o movimento que Pêcheux (1990a) realiza em obras como "Discurso: estrutura ou acontecimento?", em que chega a abandonar o conceito de formação discursiva, preferindo a concepção de interdiscurso e admitindo as falhas no ritual de interpelação, como já fez no artigo "Delimitações, inversões, deslocamentos":

[...] levar até às últimas consequências a interpelação ideológica como ritual supõe o reconhecimento de que não há ritual sem falha, desmaio ou rachadura: 'uma palavra por outra' é uma definição (um pouco restritiva) da metáfora, mas é também o ponto em que um ritual chega a se quebrar no lapso ou no ato falho. (PÊCHEUX, 1990b, p. 17).

Essa concepção de falha no ritual junto à perspectiva de tomada de posição do sujeito, que veremos nas próximas seções, nos leva a uma visão de sujeito que é influenciado pelas ideologias, mas não está acorrentado a elas, pois pode tomar consciência de suas posições. Partindo desses deslocamentos e excluindo a desidentificação como uma tomada de posição possível neste momento, tomamos as tomadas de posição de identificação e contraidentificação como relativas aos discursos de formações discursivas, esta usada 
como agrupamento de discursos e não como entidade que pré-estabelece o dizer do sujeito, a fim de iniciarmos o deslocamento que propõe Pêcheux (1990a, 1990b).

Para elucidar esses conceitos e iniciar as análises propriamente ditas dos percursos dos alunos nas respostas às questões, realizamos uma explanação sobre nossos percursos metodológicos de aplicação da pesquisa e uma análise do texto que utilizamos como base para elaboração do questionário, de forma a apontar os discursos que percebemos emergir no texto-fonte e analisar como os alunos tomam posição frente a esses discursos.

\section{PERCURSOS METODOLÓGICOS E ANÁLISE DISCURSIVA DO TEXTO- FONTE}

Para desenvolvimento desta pesquisa, a coleta de dados se realizou no espaço da disciplina "Prática de Leitura e Produção de Textos" em sua oferta nos cursos de Matemática e Enfermagem; e da disciplina "Língua Portuguesa", oferecida para o curso de Jornalismo. A escolha pelo espaço dessas disciplinas foi o contato direto com os professores, que são do Departamento de Letras da Universidade Federal do Rio Grande do Norte (UFRN), o que possibilitou a articulação do processo, além de serem disciplinas com foco na leitura e produção de textos, de forma que nossa coleta se adequava às atividades propostas pelas disciplinas e poderia ter maior adesão dos sujeitos de pesquisa. Já a escolha dos cursos em que a disciplina é ofertada se deu pelo interesse em dados de cursos distintos, que pudessem representar grandes áreas da UFRN para um estudo comparativo dos textos: Jornalismo, como representante da área de humanas; Matemática, como representante da área de exatas; e Enfermagem, como representante da área de saúde.

No âmbito desta disciplina, propusemos aos alunos a leitura do artigo "Poder e ética na pesquisa social" (DEBERT, 2003), em que a autora discute a ética na pesquisa, o surgimento e eficácia de normas éticas, propondo uma reflexão acerca de como deve se constituir um código de ética pertinente. Por meio desse texto, que traz como tema central a ética na pesquisa, considerado 
por nós um tema que perpassa (ou deve perpassar) todos os cursos da instituição, os alunos responderam ao questionário proposto.

O processo de coleta ocorreu no semestre de 2019.2, contando com 21 respostas na coleta 1, na turma destinada ao curso de Matemática; 16 respostas na coleta 2, na turma destinada ao curso de Enfermagem; e 24 respostas na coleta 3, na turma destinada ao curso de Jornalismo, totalizando 61 textos. Desse total, todos foram lidos e integraram um mapeamento inicial das tomadas de posição. Para este artigo, escolhemos o percurso de um aluno da coleta 1, que apresenta aspectos recorrentes em todas as coletas, como mostramos adiante.

Em relação a questões éticas, apresentamos aos alunos nossa pesquisa, aprovada pelo comitê de ética sob o Certificado de Apresentação para Apreciação Ética (CAAE) número 15855619.0.0000.5537; explicamos para os alunos seus direitos, dentre eles a possibilidade de desistirem de participar da pesquisa e o fato de mantermos o anonimato desses alunos no instrumento de pesquisa e na escrita da dissertação. Esses elementos estão descritos no termo de consentimento livre e esclarecido (TCLE), que foi assinado pelos sujeitos da pesquisa, conforme estabelecido pelo comitê de ética da UFRN (Resolução 466/12 do Conselho Nacional de Saúde).

A fim de manter o anonimato dos sujeitos de pesquisas, eles serão denominados de acordo com o número atribuído a eles e suas coletas, de acordo com a quantidade de respostas obtidas em cada coleta e a ordem de realização delas. Isto é, o percurso analisado neste artigo, por exemplo, será do primeiro aluno avaliado na coleta 1, de modo que seu código será A1C1. Por sua vez, suas respostas serão sinalizadas de acordo com número da questão correspondente, como pode ser observado nas análises presentes na seção seguinte.

O texto-fonte utilizado, o artigo "Poder e ética na pesquisa social", foi escrito por Guita Grin Debert, professora titular do Departamento de Antropologia da UNICAMP, e publicado na revista "Ciência e Cultura" em 2003. Para uso em sala de aula, fizemos uma adaptação do texto, em que unimos alguns parágrafos e retiramos as notas de rodapé para que o texto se tornasse menor e mais 
adequado para impressão. Tendo em vista que foi a versão que os alunos leram, ela será nosso referencial. A fim de compreendermos as relações estabelecidas entre os discursos do texto-fonte e as produções dos alunos, realizamos uma análise discursiva do artigo para guiar a análise dos textos dos alunos.

O texto tem como cerne a discussão sobre os dilemas na criação de um código de ética para o desenvolvimento de pesquisas com seres humanos e traça um breve percurso histórico da modificação da concepção do que é uma pesquisa que pode ser considerada ética em suas práticas para com os sujeitos de pesquisa, além de trazer questões para provocar o leitor acerca dos obstáculos para criação de um código de ética que não seja nem tão vago e aberto, sem garantir proteção para os participantes, e nem tão burocrático e restrito ao ponto de ser um entrave à realização de pesquisas.

O texto parece partir do que podemos chamar, a partir de Pêcheux (2014), de uma formação discursiva (FD) sobre prática de pesquisa, da qual alguns de seus discursos são evocados, referentes ao foco dado aos procedimentos de pesquisa e em quem estão centrados os interesses e os direitos dentro de uma pesquisa. Apesar dessa multiplicidade, enfocamos apenas três discursos percebidos no texto-fonte, pois os consideramos mais relevantes em relação às tomadas de posição que surgiram nos textos dos alunos.

Como mencionado anteriormente, salientamos que não estamos tomando FD num sentido homogeneizante de sujeitos e de discursos, como se não houvesse escapatória ou possibilidade de deslocamento à produção de discursos dos sujeitos. Neste trabalho, tomamos a ideia de FD como um agrupamento de discursos que possuem similaridades entre si. Neste caso, entendemos que os discursos que emergem no texto-fonte são relativos (principalmente) a uma FD sobre prática de pesquisa e apontam para definir a importância dos direitos e interesses dos participantes da pesquisa, cada um sob seu próprio viés, de modo que entendemos a FD como um princípio de agrupamento, mas não de restrição dos discursos e percebemos as tomadas de posição como relativas a esses discursos.

Dentro dessa FD sobre prática de pesquisa, percebemos a emergência de três discursos principais. O primeiro discurso que observamos (D1) elege os 
interesses do pesquisador (e da pesquisa) como mais importantes que os interesses dos sujeitos de pesquisa, ou seja, o poder de decisão sobre a pesquisa está nas mãos do pesquisador. D1 pode ser percebida nas epígrafes do artigo, em que constatamos a fala de Nogueira (1977) e Portelli (1997), ambos, mesmo com 20 anos de distância entre as falas, admitiram a necessidade de se fazer "manipulações éticas", tais como omissão da realização da pesquisa em si, como sugere Nogueira (1977), omissão dos objetivos da pesquisa etc., em prol de obter resultados mais "verdadeiros" e/ou de deixar os sujeitos de pesquisa mais confortáveis na participação da pesquisa.

Debert (2003) aponta um distanciamento de D1 na maneira como é concebido por Nogueira (1977), em que se admite a omissão da realização da pesquisa, mas não se distancia completamente da forma como esse discurso é percebido por Portelli (1997), pois compreende que, pelo fato de o autor estar lidando com grupos poderosos, no caso uma elite religiosa, seria admissível ocultar os objetivos de pesquisa para conseguir adentrar no mundo do sujeito de pesquisa.

A partir dessa fala, a autora comenta que a pesquisa com grupos poderosos, de que trata Portelli — e da qual a autora não sugere distanciamento —, não é tão discutida em termos éticos e que o foco tem se assentado em pesquisas com grupos desprivilegiados e minorias. Nessa perspectiva, a autora traz o foco para os grupos pesquisados, que, como se encontram em posição de vulnerabilidade em relação aos pesquisadores, devem ter os seus interesses colocados acima dos interesses da pesquisa e as discussões sobre consentimento, capacidade legal e intelectual de compreensão da pesquisa e afins estão mais presentes nessa modalidade de pesquisa.

Por meio dessas falas, percebemos a emergência de outro discurso, D2, em que os interesses dos sujeitos de pesquisa têm privilégio sobre os interesses do pesquisador (e da pesquisa), isto é, o poder de decisão sobre a pesquisa está nas mãos do sujeito de pesquisa, no sentido de que seus interesses estão acima do "sucesso" da pesquisa. Percebemos que a autora sugere esse poder de decisão para o trabalho com grupos em situação de vulnerabilidade, mas que não se opõe às manipulações éticas em relação ao trabalho com grupos 
poderosos citado por Portelli. Vemos que a autora já está criando embates entre discursos, pois marca que, na perspectiva de trabalho com grupos desprivilegiados, os sujeitos de pesquisa devem ter seus interesses e direitos colocados em primeiro lugar, o que abre a possibilidade de que com outros grupos a visão seja diferente. Ao trabalhar com grupos vulneráveis, Debert (2003) traz a importância de se discutir consentimento do sujeito, as informações que deve receber, a capacidade de compreendê-las e, também, a necessidade de se avaliarem os riscos envolvidos na pesquisa com minorias sociais.

Nesse âmbito, a autora reafirma a centralidade da Antropologia para as discussões acerca desses riscos e da criação de um código de ética, já que a disciplina tem como essência o trabalho com uma ampla variedade de culturas humanas e foi a primeira das ciências humanas a elaborar um código de ética. Essa discussão traz para o centro o sujeito de pesquisa como foco das escolhas na realização da pesquisa, uma manutenção de D2 como discurso que privilegia os interesses desses sujeitos. Em seguida, a autora traz a necessidade de se romper com a "cegueira normativa", conceito que traz de Richard Falk (1992), em que grupos desprivilegiados são vistos como um retrocesso à modernização por grupos ocidentais, considerados desenvolvidos.

Em seguida, percebemos uma transição para a aparição de outro discurso, pois Debert (2003) aponta que alguns grupos pesquisados, como os indígenas, já contam com assistência jurídica para se protegerem de ações antiéticas. A autora evidencia como as modificações na relação pesquisadorpesquisa-sujeitos-de-pesquisa nos afastam das práticas mostradas nas epígrafes e correspondentes à D1.

A partir dessa consideração, percebemos o desenvolvimento de um terceiro discurso, D3, ao qual a autora parece se filiar, em que o foco está na conciliação entre os interesses dos pesquisadores e dos sujeitos de pesquisa, ou seja, o poder de decisão sobre a pesquisa está nas mãos de ambos. Debert (2003) traz a necessidade do código de ética ser não só uma defesa dos sujeitos de pesquisa, mas também dos pesquisadores e da comunidade de pesquisa, pois acredita que deve-se ampliar o debate para situações em que os grupos pesquisados estão em situação de poder em relação aos pesquisadores, como 
em pesquisas com elites religiosas e políticas (como o trabalho de Portelli citado na segunda epígrafe), e que é preciso levar em consideração as novas agendas de pesquisa, que podem influenciar a vida em sociedade:

\begin{abstract}
Essas questões e os debates em torno delas devem, no entanto, ser ampliados de modo a dar conta de outras situações em que a desigualdade entre pesquisador e pesquisado não é tão evidente, como no caso dos estudos com elites religiosas ou políticas. É preciso ainda levar em conta as novas agendas de pesquisa, apresentadas num contexto em que o conhecimento científico produzido polariza aspectos fundamentais da vida social em escala planetária. (DEBERT, 2003, p. 2, grifos nossos).
\end{abstract}

Dessa forma, percebemos que há um D3, uma postura conciliadora, mas que ela já parece se encontrar em embate com D1, pois vemos a sugestão da autora em olhar para situações em que o pesquisador se encontra também numa situação de desigualdade, como ao trabalhar com grupos poderosos, o que traz à tona certo foco no pesquisador e uma indicação de que se deve ter outro procedimento quando o pesquisador é quem se encontra em situação de desigualdade com o sujeito de pesquisa.

Esse embate reaparece em vários momentos, pois a autora considera importante tratar de forma distinta os pesquisadores e as pesquisas quando os pesquisadores se encontram em uma situação desfavorável, trabalhando com grupos poderosos, e isso pode ser percebido também no fechamento do artigo:

Não podemos desconhecer a força e o sentido que as exigências éticas da pesquisa ganham hoje em dia, tampouco que os pesquisadores têm que estar armados para esse tipo de exigência num contexto em que os recursos da pesquisa e o interesse por ela se ampliaram enormemente. É imprescindível dispormos de um código de ética da pesquisa científica, porque ele oferece também uma proteção ao pesquisador e à comunidade científica. Obviamente, um código não substitui o bom senso e não elimina as discussões que empreendemos sobre os dilemas éticos enfrentados em diferentes contextos. Contudo, propor um código de ética é uma tarefa monumental. Como criar um código de ética que não imponha a todas as disciplinas parâmetros específicos exclusivos da pesquisa em certas áreas disciplinares? Como criar um código que não seja tão vago a ponto de não poder impor limites a certas práticas de 
pesquisa, e que seja tão restritivo e exija procedimentos lentos e burocratizados que inviabilize a investigação e perca o respeito dos pesquisadores? Será que para renovar nossa agenda de pesquisa e garantir a relevância democrática da nossa disciplina só nos resta fazer manipulações éticas em nome de boas causas? (DEBERT, 2003, p. 3, grifos nossos).

Após a apresentação de três perspectivas principais, três discursos, a autora parece confirmar que o discurso que assume como principal é D3, mais conciliador, pois reconhece a importância de guiar a pesquisa sob as exigências éticas para com os sujeitos de pesquisa, mas também de ter um código de ética que proteja a comunidade científica. A partir dessas considerações, Debert (2003) afirma que os códigos de ética não eliminam a necessidade de se ter bom senso e de discutir sobre os dilemas éticos em diferentes contextos, mas que é imperativo se ter um código de ética e que isso envolve diversas questões, em especial as elencadas no excerto acima.

Por se situar na pesquisa em Antropologia, suas questões estão mais voltadas para a prática da pesquisa, como a imposição de procedimentos de outras disciplinas por meio do código de ética, isto é, a ausência de parâmetros específicos para áreas diferentes. A segunda questão parece trazer de forma mais evidente D3, pois se preocupa com a criação de um código que não seja tão vago a ponto de permitir práticas antiéticas, nem tão restrito a ponto de ser extremamente burocrático e entravar as pesquisas, de modo que há o indício dessa postura conciliadora como dominante na fala de Debert (2003). No entanto, a última questão traz novamente D1, pois há a provocação de que talvez "manipulações éticas" devam ser feitas para renovação das agendas de pesquisa e garantia da relevância democrática para a Antropologia, o que traz novamente os interesses do pesquisador e da pesquisa como focos nas práticas das pesquisas.

Dessa forma, situadas na região da Ética da formação ideológica, destacamos três discursos principais que emergem no artigo de Debert (2003). D1, que tem como discurso principal o primado dos interesses do pesquisador e da pesquisa sobre os dos sujeitos de pesquisa e que, por ter esse foco, admite "manipulações éticas" em favor dos objetivos de pesquisa; D2, em que os 
interesses dos sujeitos de pesquisa são superiores aos demais, de modo que não se admite a omissão ou nebulosidade das informações sobre as pesquisas de que estão participando; e D3, que tem como foco a conciliação entre os interesses do pesquisador e dos sujeitos de pesquisa.

A partir dessas considerações, em especial dos discursos principais apontados e da postura assumida por Debert (2003), analisamos o percurso dos alunos na resposta às questões (incluindo a proposta de escrita de resenha crítica).

\section{AS TOMADAS DE POSIÇÃO E SUA EMERGÊNCIA NO PERCURSO DOS ALUNOS}

Tomamos a análise discursiva do texto-fonte para a resposta às questões como guia para análise dos percursos dos alunos em suas respostas até a produção da resenha crítica. Dessa forma, sabendo que nós também não somos neutros, analisamos como os alunos desenvolveram suas respostas (incluindo suas resenhas críticas) e que tomadas de posição (identificação e contraidentificação) emergiram em relação às formações discursivas elencadas anteriormente, tentando perceber como os alunos realizaram leituras do textofonte e o que essas leituras nos indicam acerca do modo de escrita deles. Por meio de nossas análises, já podemos perceber que os alunos tendem a assumir a postura conciliadora relativa à D3 ou a postura de priorizar os interesses dos sujeitos de pesquisa, de D2, mas não há plena identificação com um discurso ou outro, mas embates entre eles.

Para representar elementos que foram recorrentes nas coletas, escolhemos o aluno 1 da coleta 1 (A1C1) para analisarmos seu percurso desde a resposta à questão 1 até a produção da resenha crítica. A resposta à questão 1, "A autora afirma que a Antropologia foi a primeira das ciências humanas a elaborar um código de ética. Qual a razão que ela apresenta para esse fato?", diz respeito a uma espécie de "captação de ideias do texto-fonte", em que o aluno poderia encontrar de forma mais evidente a resposta já disposta no texto. A resposta fornecida pelo aluno 1 foi a seguinte: 
A autora associa esse fato ao vasto acervo de pesquisas realizadas pela antropologia ao longo da história. (R1A1C1, grifos nossos).

Percebemos em R1A1C1 que o aluno priorizou o acervo da Antropologia como justificativa para que a disciplina tenha sido a primeira das Ciências Humanas a desenvolver um código de ética, em detrimento da justificativa que Debert (2003) indica no $11^{\circ}$ parágrafo, em que é a essência da disciplina, o estudo da diversidade cultural, que motivou a preocupação com a ética. Provavelmente, para o aluno (assim como indicam outros graduandos), o acervo, o conhecimento construído por uma disciplina é que suscitam a necessidade de construção de um documento como um código de ética e não a natureza da disciplina, como a autora sugere ser a razão da Antropologia ter se voltado para essa problemática ética.

Além de considerar a experiência da disciplina mais justificativa que a prática inerente a ela - o trabalho com seres humanos - , é possível que 0 aluno tenha realizado uma leitura superficial do texto e, como o comentário sobre o acervo da Antropologia aparece em alguns parágrafos do texto - inclusive a palavra "acervo" é repetida 3 vezes ao longo do texto - , A1C1 pode ter compreendido que essa é a única justificativa para a questão 1 , sem ler de forma mais atenta o trecho em que essa criação do código de ética é apresentada, em que percebemos a ênfase à própria prática da disciplina como elemento que suscitou a necessidade de se criar um código de ética:

Tendo se voltado para o estudo da ampla variedade de culturas humanas, particularmente para o estudo desses grupos desprivilegiados, a Antropologia foi a primeira disciplina das ciências humanas a elaborar um código de ética. (DEBERT, 2003, p.2).

Em relação a aspectos estruturais, notamos que não há uma reformulação da questão inserida na resposta para que o intuito da questão 
ressurja no texto, o único elemento de retomada da pergunta está em "esse fato", grifado anteriormente.

Assim, percebemos uma estrutura de resposta semelhante ao que costumamos ver com alunos da educação básica, em que a questão geralmente não é retomada, provavelmente porque o aluno sabe que seu único leitor será o professor e, como ele quem elaborou a questão, a pergunta pode ser por ele recuperada. Outro aspecto a ser destacado é a reprodução quase ipsis litteris do que estava posto no texto-fonte (grifos nossos):

Quadro 1 - Comparação entre R1A1C1 e Texto-fonte

\begin{tabular}{|l|l|}
\hline \multicolumn{1}{|c|}{ R1A1C1 } & \multicolumn{1}{|c|}{ Texto-fonte } \\
\hline $\begin{array}{l}\text { A autora associa esse fato ao vasto } \\
\text { acervo de pesquisas realizadas pela } \\
\text { antropologia ao longo da história. }\end{array}$ & $\begin{array}{l}\text { Intrinsecamente envolvida com o estudo } \\
\text { da diversidade cultural, a Antropologia, } \\
\text { ao longo de sua história, acumulou um } \\
\text { rico acervo sobre as formas pelas quais }\end{array}$ \\
$\begin{array}{l}\text { a vida social é produzida em diferentes } \\
\text { contextos. (DEBERT, 2003, p.1). }\end{array}$ \\
\hline
\end{tabular}

Fonte: autoria própria.

Tendo em vista a natureza da questão, que visava a identificação de uma resposta no texto, não seria surpreendente que as respostas fossem mais similares ao texto-fonte, mas é válido perceber como esse processo de paráfrase ocorre nessa questão e como se repete nas demais. Paráfrases como as realizadas em $\mathrm{R} 1 \mathrm{~A} 1 \mathrm{C} 1$ podem ser consideradas paráfrases de sinonímia, tal como definidas por Fuchs (1985), em que a produção se constitui com escolhas lexicais semelhantes ao texto-fonte, formulações que estabelecem relação de sinonímia com ele. Essa paráfrase de sinonímia aparece de forma mais clara nas expressões grifadas em R1A1C1 e suas expressões "correspondentes" no texto-fonte: vasto acervo/ rico acervo; antropologia/ Antropologia; e ao longo da história/ ao longo de sua história.

Dessa forma, apesar de a questão 1 ter uma natureza que possibilita a repetição, já percebemos a tendência à reprodução do texto-fonte, que se repetiu em várias respostas de alunos em todas as coletas. Como se trata de uma reprodução, sem acréscimo de um comentário do aluno, não podemos afirmar 
que há uma identificação com algum discurso, pois, pela natureza da questão, a repetição pode ter ocorrido apenas para o cumprimento da atividade e não como forma de se filiar a alguma fala.

A resposta à questão 2, "O que seria essa 'cegueira normativa' de que trata a autora?", apresentada por A1C1 se construiu da seguinte maneira:

Esta expressão representa uma visão da modernização em que algumas culturas aparecem representando atraso a ser superado para o bem delas próprias. (R2A1C1)

Essa questão exigia mais do que a anterior no sentido de que, no lugar de buscar uma espécie de chave de resposta, deve-se compreender um conceito que Debert (2003) traz de Richard Falk (1992) e explicá-lo. Em R2A1C1, vemos novamente a paráfrase de sinonímia, isto é, a paráfrase que se constitui por meio de uma reformulação, equivalente em sentido, por meio da escolha de um léxico similar ao do texto-fonte. Nesse caso, notamos que a formulação se constitui quase como uma cópia do texto fonte, como podemos perceber no quadro a seguir (grifos nossos):

Quadro 2 - Comparação entre R2A1C1 e Texto-fonte

\begin{tabular}{|l|l|}
\hline R2A1C1 & \multicolumn{1}{|c|}{ Texto-fonte } \\
\hline Esta expressão representa uma & Essa expressão, cunhada por Richard \\
visão da modernização em que & Falk (1992), caracteriza uma visão da \\
algumas culturas aparecem & modernização em que as culturas \\
representando atraso a ser & não-ocidentais, mas também os \\
superado para o bem delas & $\begin{array}{l}\text { pobres, as minorias étnicas e religiosas, } \\
\text { próprias. }\end{array}$ \\
& $\begin{array}{l}\text { outros grupos desprivilegiados } \\
\text { aparecem como expressões de um } \\
\text { atraso a ser superado para o bem } \\
\text { desses próprios grupos. (DEBERT, } \\
\text { 2003, p.2) }\end{array}$ \\
\hline
\end{tabular}

Fonte: autoria própria.

Por meio do Quadro 2, podemos perceber que as expressões grifadas são idênticas, mas podemos considerar como paráfrase de sinonímia do texto- 
fonte pelas alterações realizadas. Apesar de não ser fruto de uma reformulação discursiva (FUCHS, 1985), ou seja, não poder ser considerada como uma formulação que indique uma interpretação própria do sujeito, o texto responde à pergunta, pois apresenta o conceito requisitado e marca que não é uma visão do aluno, mas uma "visão da modernização", que percebe grupos minoritários como afetados pela percepção de que eles se constituem como um atraso a essa modernização. Como se apresenta de forma muito sucinta e semelhante ao texto-fonte, não podemos ter certeza de que o aluno compreendeu o conceito e que opiniões ele tem sobre essa "visão da modernização", apenas temos a reprodução do que foi dito por Debert (2003) e, por consequência, Richard Falk (1992).

A questão 3, "qual a sua opinião sobre as questões da ética na pesquisa?", abre mais espaço para um posicionamento que pode estar mais desvinculado do texto-fonte porque se volta para o sujeito, "sua opinião". O A1C1 apresenta em $\mathrm{R} 3 \mathrm{~A} 1 \mathrm{C} 1$ a seguinte resposta:

$\mathrm{Na}$ minha opinião, o pesquisador deve deixar muito claro suas intenções com os dados coletados, bem como explicar para o pesquisado informações sobre onde será publicado tal documento contendo 0 resultado. (R3A1C1, grifos nossos).

Ao construir sua resposta, $A 1 C 1$ indica sua identificação com $D 2$, em que o foco está nos interesses dos sujeitos de pesquisa, como pode ser percebido na preocupação que $\mathrm{A} 1 \mathrm{C} 1$ demonstra na clareza dos objetivos de pesquisa ("as intenções com os dados coletados") e na forma como as informações vão ser publicizadas pelo pesquisador. Dessa forma, sua opinião se volta unicamente para o que tange ao sujeito de pesquisa nos procedimentos éticos, que indica sua identificação com D2, sem tomadas de posição de contra-identificação, isto é, A1C1 não realiza concessões, insere debates dentro da D2 ou mostra deslocamentos para outro discurso, de modo que percebemos apenas a tomada de posição de identificação com D2 e o foco se volta somente para o sujeito de pesquisa e seus direitos, sem deslocamentos nem para D1, em que o foco está 
no pesquisador e suas necessidades, nem para D3, em que há uma postura de conciliação entre interesses do pesquisador e do sujeito de pesquisa.

Nessa questão percebemos que há uma construção que está vinculada ao texto-fonte, mas que não se constitui como paráfrase de sinonímia como nas respostas anteriores, mas como uma paráfrase discursiva, de reformulação que parte de uma interpretação do texto-fonte e que indica D2 como discurso dominante no texto de $\mathrm{A} 1 \mathrm{C} 1$ e já sugere que esse será seu posicionamento na construção da resenha.

Por meio da proposta da resenha crítica, inserida na questão 4, "A partir da leitura do texto e das questões que você respondeu, produza uma resenha crítica, isto é, um texto com a sua opinião acerca do artigo lido", A1C1 construiu a resenha $\mathrm{R} 4 \mathrm{~A} 1 \mathrm{C} 1$ :

Na última década, observou-se um incentivo à pesquisa no Brasil. Com a ampliação das vagas de graduação e pós-graduação, bem como das bolsas de pesquisa oferecidas aos estudantes, despertou 0 interesse pela pesquisa por muitos desses estudantes. Com isso, o assunto pesquisa, e consequentemente, ética na pesquisa ganhou considerável relevância.

Sobre tal tema, a professora universitária Guita Grin, escreveu um excelente texto, com título: 'Poder e ética na pesquisa social'. Nesse texto ela destaca, por exemplo, um assunto muito pertinente, que é a importância dos resultados publicados em pesquisas não constranger, humilhar ou trazer prejuízos à população estudada. Pois sabe-se que a pesquisa tem finalidade de realizar alguma constatação, a qual deve orientar condutas que tragam benefícios à população de uma forma geral. A autora também aborda no texto questionamentos sobre a autoria e posse dos resultados obtidos, fato que apesar de não haver uma definição apresenta grande relevância. Dessa forma, o texto se mostra enriquecedor, pois desperta no leitor o interesse pelo assunto. (R4A1C1, grifos nossos)

A R4A1C1 é estruturada com um parágrafo de introdução, em que A1C1 traz o tema central do texto-fonte, a ética na pesquisa, como relevante pelo incentivo à pesquisa no Brasil por meio da ampliação de vagas na graduação e pós-graduação e a implementação de bolsas de pesquisa. Essa introdução parece indicar que o aluno desenvolverá reflexões levando em consideração também o pesquisador e não só o sujeito de pesquisa, já que traz a ética como 
relevante não por uma necessidade relativa ao trabalho com seres humanos, mas pelo desenvolvimento da pesquisa e do ensino superior como um todo no país, de modo que o foco se assenta no lugar de onde prioritariamente partem as pesquisas: as universidades.

Tendo em vista que anteriormente o aluno indicou sua identificação com D2, em que o foco está nos sujeitos de pesquisa, o desenvolvimento desse parágrafo sugere um deslocamento para D3 (conciliação entre os interesses de pesquisador e sujeito de pesquisa), pois esse discurso comporta a posição do pesquisador, diferente de D2, em que há a primazia dos interesses dos sujeitos de pesquisa.

Após o parágrafo de introdução da temática, $\mathrm{A} 1 \mathrm{C} 1$ entra no texto-fonte propriamente dito e o avalia como "excelente". Apesar de inicialmente ter indicado o incentivo à pesquisa e à presença dos pesquisadores, os discursos que o aluno destaca como "pertinentes" em seu texto são relativos aos sujeitos de pesquisa, como a importância da pesquisa não prejudicar a população que está sendo pesquisada, e o fato de que a pesquisa deve beneficiá-la, de forma que o foco parece se assentar nos sujeitos de pesquisa (D2) e não no pesquisador ou numa conciliação entre ambos:

Quadro 3 - Comparação entre R4A1C1 e Texto-fonte

\begin{tabular}{|c|c|}
\hline $\mathrm{R} 4 \mathrm{~A} 1 \mathrm{C} 1$ & Texto-fonte \\
\hline $\begin{array}{l}\text { Sobre tal tema, a professora universitária } \\
\text { Guita Grin, escreveu um excelente texto, } \\
\text { com título: 'Poder e ética na pesquisa social'. } \\
\text { Nesse texto ela destaca, por exemplo, um } \\
\text { assunto muito pertinente, que é a } \\
\text { importância dos resultados publicados } \\
\text { em pesquisas não constranger, humilhar } \\
\text { ou trazer prejuízos à população estudada. } \\
\text { Pois sabe-se que a pesquisa tem finalidade } \\
\text { de realizar alguma constatação, a qual deve } \\
\text { orientar condutas que tragam benefícios à } \\
\text { população de uma forma geral. (grifos } \\
\text { nossos). }\end{array}$ & $\begin{array}{l}\text { Avaliam-se, também, os riscos envolvidos na } \\
\text { publicação dos resultados, porque nossas } \\
\text { conclusões não podem constranger, } \\
\text { humilhar ou trazer prejuízos para as } \\
\text { populações estudadas. } \\
\text { (DEBERT, 2003, p.2, grifos nossos). }\end{array}$ \\
\hline
\end{tabular}

Fonte: autoria própria. 
Por meio da comparação, percebemos que o aluno realiza praticamente uma cópia do texto-fonte, cujas alterações nos levam a definir esse trecho como mais uma paráfrase de sinonímia. Diferente das respostas às questões 1 e 2, em que não há uma marcação de tomada de posição, a reprodução do texto-fonte nesse caso nos indica uma tomada de posição de identificação com D2, pois é acompanhada pela avaliação do aluno de que a discussão sobre a proteção dos sujeitos de pesquisa é um "assunto muito pertinente", que marca sua identificação com esse discurso que foca nos pesquisados.

Em seu parágrafo final, A1C1 retoma as discussões de Debert (2003) sobre autoria e posse dos dados obtidos, mas afirma que não há respostas para os questionamentos suscitados, embora eles sejam relevantes. Os questionamentos a que o aluno se refere dizem respeito também à participação dos sujeitos de pesquisa, pois a autora faz provocações acerca do reconhecimento desses sujeitos como autores e proprietários dos dados e, consequentemente, da pesquisa.

Assim, como sugerido em R3A1C1, o discurso dominante nas falas de $A 1 C 1$, aquela a que ele mais toma posição de identificação, é $D 2$, que prioriza os interesses dos sujeitos de pesquisas sobre os demais. No entanto, como o aluno também menciona pesquisadores e a pesquisa em si ao longo do texto, podemos perceber que há a influência de D3 em meio à dominância da D2, pois o aluno faz emergir em seu texto outros elementos da pesquisa que não são relativos apenas aos sujeitos de pesquisa e avalia o texto-fonte, que tem como discurso dominante D3, como "excelente" e "enriquecedor", de modo que há indícios da dominância de D2, mas em embate com D3, embora o aluno não explicite esse deslocamento.

\section{CONSIDERAÇÕES FINAIS}

Por meio das análises, percebemos ser mais adequado centrar as tomadas de posição como referentes a discursos e não a formações discursivas, pois esse deslocamento nos permite perceber as nuances dos posicionamentos dos alunos em relação aos discursos que emergem no texto-fonte e nos leva a 
compreender que não é possível uma identificação plena. Isto é, embora seja possível observar a dominância de um discurso, a identificação com esse discurso não é plena; ela aparece em embate com outros discursos tanto no texto-fonte quanto nas respostas analisadas.

Em relação aos posicionamentos construídos, constatamos que os alunos tendem a se identificar com discursos que privilegiam os interesses dos sujeitos de pesquisa. Essa identificação pode indicar tanto que os alunos não possuem experiência com o desenvolvimento de pesquisas, o que justificaria por que os graduandos não se colocam na posição de pesquisadores, isto é, não assumem espontaneamente posturas que enfocam os interesses do pesquisador; quanto que os alunos e consideram parte desses grupos vulneráveis e, por isso, asseveram a necessidade de proteger e assegurar os direitos desses grupos.

Outro ponto a ser destacado é o fato de que os alunos só indicam tomadas de posição quando isso é expressamente requerido na questão, ou seja, quando as questões possuem um aspecto mais "conteudista", os alunos geralmente se restringem a reproduzir o texto-fonte, parafraseá-lo — na forma de paráfrases de sinonímia - , sem emitir comentários. Essa repetição muitas vezes reaparece na produção da resenha crítica, mas é acompanhada de uma tomada de posição marcada linguisticamente, como pudemos observar nas análises.

A reprodução do texto-fonte nos leva a refletir sobre como esses alunos compreendem a escrita acadêmica, se a repetição do que está posto é tão presente que até para construir um posicionamento próprio em uma atividade eles precisam recorrer à reprodução dos dizeres de um autor; ou se isso é "apenas" parte de uma necessidade de finalizar rapidamente uma atividade requerida e à qual não será atribuída nota.

\section{REFERÊNCIAS}

BARBOSA, M. V.; FABIANO-CAMPOS, S. A difícil arte de dialogar com a palavra do outro para produzir a palavra própria. Interdisciplinar, Itabaiana, ano 9, v.20, jan./jun. 2014, p. 35-46. 
DEBERT, G. G. Poder e ética na pesquisa social. Ciência e Cultura, Campinas, v.55, n.3, p.30-32, 2003.

FABIANO-CAMPOS, S. A prática da pesquisa como sustentação da apropriação do conhecimento na graduação em Letras. 2007. 210 f. Tese (doutorado) - Universidade Estadual Paulista, Faculdade de Ciências e Letras de Araraquara, 2007. Disponível em: <http://hdl.handle.net/11449/103601>.

FUCHS, C. A paráfrase linguística: equivalência, sinonímia ou reformulação? Caderno de Estudos Linguísticos, Campinas, n.8, p.129-134, 1985. Tradução: Wanderley Geraldi.

GINZBURG, C. Sinais: raízes de um paradigma indiciário. In: GINZBURG, C. Mitos, emblemas, sinais, morfologia e história. São Paulo: Companhia das Letras, 1989. p. 143-179.

INDURSKY, F. Da interpretação à falha no ritual: a trajetória teórica da noção de Formação Discursiva. In: BARONAS, R. L. (Org.). Análise do Discurso: apontamentos para uma história da noção-conceito de formação discursiva. São Carlos: Pedro \& João Editores, 2007, p. 75-87.

PÊCHEUX, M. Delimitações, inversões e deslocamentos, Cadernos de Estudos Linguísticos, Campinas, n. 19, p. 7-24 jul./dez. 1990b.

PÊCHEUX, M. Discurso: estrutura ou acontecimento. Campinas: Pontes Editores, 1990a.

PÊCHEUX, M. Semântica e discurso: uma crítica à afirmação do óbvio. 5 ed. Campinas: Editora da UNICAMP, 2014.

PINHEIRO, R. C. Análise discursiva de tomadas de posição em textos de graduandos da UFRN. 2021. 115f. Dissertação (Mestrado em Estudos da Linguagem) - Natal: Universidade Federal do Rio Grande do Norte, 2021.

SILVA, J. C.; ARAÚJO, A. D. A metodologia de pesquisa em Análise do Discurso. Grau Zero: Revista de Crítica Cultural, v. 5, n. 1, p. 17-31, 2017.

VIEIRA, J. A. A escrita do texto acadêmico na graduação: modos de utilização de conceitos teóricos de uma área de conhecimento. 2013. 119 f. Dissertação (Mestrado em Linguística Aplicada; Literatura Comparada) - Universidade Federal do Rio Grande do Norte, Natal, 2013. 